\title{
DIFICULTADES POLÍTICAS DE TRAJANO (LOS AÑOS 107-112)
}

\author{
TRAJAN'S POLITICAL DIFFICULTIES (A.D. 107-112) \\ PILAR GONZÁLEZ-CONDE \\ Universidad de Alicante
}

\begin{abstract}
Resumen. Este trabajo trata el período de estancia de Trajano en Roma entre el final de la segunda guerra dácica y el giro político ca. 112 a través del mensaje político en las monedas y, especialmente, como explicación a la aparición de la leyenda DACIAAUGUSTA PROVINCIA en acuñaciones de los años 112-114 d.C.

Palabras clave. Trajano, Roma, numismática, Dacia
\end{abstract}

\begin{abstract}
This study discusses the period when Trajan was in Rome between the end of the Second Dacian War and the political changes of ca. 112 through the political message conveyed by coins and the explanation for the appearance of the legend DACIAAUGUSTAPROVINCIA on coins minted between 112 and 114 A.D.

Key words. Trajan, Rome, numismatics, Dacia
\end{abstract}

La conquista de Dacia durante el reinado de Trajano ${ }^{1}$ tuvo una espectacular repercusión en la imagen pública del monarca a través de los diferentes mecanismos de difusión que la administración romana tenía a su alcance y que se utilizaron para recordar a los romanos la fortaleza del sistema y la seguridad fronteriza. Para ello se representó en relieves y monedas a la personificación del territorio conquistado y luego anexionado, al Príncipe como soldado que sometía al enemigo y a éste como un caído y humillado en la batalla. Al final de la primera campaña (102), Trajano celebró un triunfo que, al menos visto con perspectiva histórica, resultaba precipitado y dejaba sin solución definitiva la situación en el bajo Danubio. Su regreso al escenario de guerra parecía indicar que la incorporación de Dacia al imperio no se contemplaba a priori y que los acontecimientos posteriores tendrían un cierto grado de improvisación, como tantas veces ocurrió en la política exterior romana.

Para entonces, Trajano había ocupado casi in absentia la más alta magistratura del estado. A su estancia en la frontera del Rin y del Danubio, después de su nombramiento, había que añadir su presencia en el escenario de la guerra contra

1. La redacción de este trabajo se ha realizado como complemento al tema principal en el marco del proyecto HUM2006 - 07904 financiado por el Ministerio de Educación y Ciencia.
Decébalo en el bajo Danubio. El 102, al terminar la primera campaña, volvió a Roma, en donde permaneció menos de tres años (antes sólo había estado durante un año y medio), saliendo en junio del 105 de nuevo hacia el frente (Kienast, 1996, 122). Cuando el año 106 terminó la segunda guerra, la proyección pública de la victoria definitiva y de la inminente anexión se intensificó, no sólo en las acuñaciones monetales sino también en el urbanismo y en el arte oficial (Strobel, 1984, passim). El Príncipe volvió a Roma para presidir la ceremonia del triunfo y reclamar los beneficios políticos de su victoria. Durante los años siguientes se produjo una considerable actividad constructiva (Gros, 2000, 227ss.; La Rocca, 2000, 251 ss.) que, en su mayor parte, se aprovechó para recordar lo que había sido la primera expansión romana más allá del Danubio.

La tarea que el Príncipe tuvo que acometer a partir del 107 estaba plagada de dificultades (González-Conde, 1991, 56-57). Es muy probable que la guerra de Dacia no fuera apoyada por todos los sectores políticos de la Urbe, pero, incluso entre sus partidarios, debió ser difícil defender la opción de una anexión que dibujaba una frontera más inestable y peligrosa que en la situación precedente. Sin embargo, la victoria le situaba en una posición menos vulnerable frente a potenciales adversarios políticos. Se iniciaba entonces una nueva etapa en el reinado que comprendería hasta su salida hacia el frente oriental y que ten- 
dría como objetivo la aceptación del monarca por todos los sectores de la sociedad romana. Trajano necesitaba demostrar en Roma que no era sólo un general victorioso, hijo de otro militar de prestigio, sino también el gestor eficaz que cuidaba de la ciudad y sus habitantes, y que el Senado había hecho la elección adecuada al aceptarle.

Cuando en el año 97 se buscaba un sucesor para el ya anciano emperador Nerva, Trajano no era, evidentemente, el único candidato posible (Bennett, 2001, 42-52). Las maniobras de las diferentes facciones políticas dejaron un rastro en el tiempo que ha permitido afirmar al prof. Alföldy que al menos había otro pretendiente al trono que contaba con muchas posibilidades, como era $M$. Cornelius Nigrinus Curiatius Maternus (Alföldy y Halfmann, 1973, 331 ss.). Trajano contaba con algunos apoyos entre los senadores hispanos y narbonenses, aunque estos no tendrían una postura unitaria (González-Conde, 1991, 142-149; Bennett, 2001, 11-26). Casi con seguridad, él no era ni siquiera el candidato de Nerva, que le adoptaría para evitar un conflicto político de máxima gravedad ${ }^{2}$. Esto explica la aptitud de Trajano años más tarde, cuando, ya como príncipe, reivindicaba la imagen de su padre biológico (Caballos, $\left.1990,305-313, n^{\circ} .167\right)$, iniciando una política dinástica que tomaría a su verdadera familia como referente de estabilidad y continuidad. Los Ulpii tuvieron entonces la fuerza de una situación social y política que les proporcionaba importantes apoyos, y reaccionaron poniendo ante el Senado a uno de sus vástagos, que contaba con una imagen en auge y con el apoyo del ejército del Rin. Su adopción en el otoño del 97 debió generar un conflicto político entre familias senatoriales que no se hizo público en toda su intensidad porque, a diferencia de lo ocurrido durante el reinado de Domiciano, la crisis no hizo explosión (Cizek, 1983, 386), aunque sí dejo rastros en los acontecimientos de los años que siguieron.

A la muerte de Domiciano, Trajano tenía ya la edad suficiente para gobernar el imperio y una carrera a sus espaldas que le proporcionaba prestigio y apoyos militares. La influencia de M. Ulpius Traianus padre podía haber funcionado ya entonces, pero no fue así. El Senado decidió elegir a uno de sus miembros, el casi anciano $\mathrm{M}$. Cocceius Nerva, como futuro príncipe. La decisión, observada en clave histórica, se ha inter-

2. Kienast, 1996, 122 fecha la adopción a finales de octubre del año 97, sin más precisión. Una recopilación de todas las noticias de las fuentes en: Bennett, 1997, 246, n. 91, con las diferentes opciones entre finales de septiembre y los primeros días de noviembre. pretado como una solución de consenso con carácter temporal. Pero lo cierto es que la edad de Nerva podía haberle permitido vivir al menos 10 años más, en cuyo caso la lucha por la sucesión se habría prolongado y la historia podía haberse escrito de otra manera. A lo largo del año 97, un sector senatorial integrado mayoritariamente por senadores hispanos y narbonenses decidió apostar por el hijo de uno de sus miembros más populares para convertirlo en cabeza del estado romano. El candidato tenía prestigio entre los soldados del ejército más poderoso de Roma, las legiones del Rin (PIR $\left.{ }^{2} \mathrm{VI}, \mathrm{n} .{ }^{\circ} 575\right)$, y probablemente se movía por los campamentos fronterizos con más familiaridad que en los círculos senatoriales romanos. Cediendo a las presiones, Nerva no habría tenido más remedio que adoptarle. Algunas monedas recuerdan la transmisión del poder y el vínculo establecido entre ellos, expresado en los bustos enfrentados de ambos como motivo de reverso. La inclusión del cognomen de su predecesor en su onomástica (Imperator Caesar Nerva Traianus) recordaba la entrada de Trajano en su nueva familia como comienzo de una alianza política que se mantuvo aún después de la muerte de Nerva, hasta que, años más tarde, se produjera la reivindicación del papel de los Ulpii.

Lejos de apresurarse a viajar a Roma, el heredero permaneció en el Rin incluso cuando el anciano príncipe había muerto y a Trajano le llegó la noticia de que acababa de sucederle. Resulta imposible alegar razones de estrategia militar para ese alejamiento de la Urbe, que hay que interpretar más bien en clave de prudencia política. El nuevo príncipe permanece allí donde se encuentra más seguro, inspeccionando los territorios fronterizos, mientras los aliados políticos de su familia se ocupan de asentar su posición en Roma. Sus acciones en el Rin y en Panonia durante los años $98-99$ probablemente no justificaban su ausencia de Roma, ya que los asuntos del limes podían haber quedado en manos de un hombre de su confianza. Cuando finalmente regresó, todo está preparado en el Senado para que Plinio reciba al monarca con un Panegíri$\mathrm{co}^{3}$ que recogía los claves políticas de la etapa

3. Entre la bibliografía que trata la intención política del Panegírico de Trajano se puede mencionar: Fedeli, 1989, 387 ss. por el análisis del tratamiento historiográfico; también Bennett, 1997, 63-66, por ser una de las más modernas monografías sobre Trajano y su entorno; Cizek 1983, 151165 , con un estudio del papel de Plinio en el entorno de Trajano y en los círculos culturales de la época; más recientemente, para una comparación entre la imagen literaria y escultórica de Trajano, especialmente a partir del Panegírico de Plinio, Trillmich, 2000, 491-494. 
que se inauguraba: la renovación del Principado en un nuevo marco de relaciones institucionales, los valores del nuevo reinado y las virtudes del monarca. Pero el texto leído en la Curia no estaba destinado al Príncipe, ni tampoco a sus aliados políticos, ni mucho menos a recabar el apoyo popular. Más bien era un aviso de la nueva situación política para aquellos que quedaran por aceptarlo, adversarios políticos que habían impulsado a sus propios candidatos y que ahora estaban ante Plinio como sector vencido. La posición del sector impulsado al poder era, sin embargo, especialmente difícil debido al recuerdo de Domiciano (Waters 1965, 389 ss.), bajo cuyo reinado se habían promocionado políticamente, gozando en algunos casos de posiciones privilegiadas. Las responsabilidades políticas del régimen anterior tenían que quedar limitadas a la persona del último de los Flavios, olvidando posibles acusaciones de colaboracionismo que hubieran acabado con algunas de las más brillantes carreras senatoriales del momento y hubieran dejado a Trajano (Caballos 1990, 308) en una situación de debilidad inasumible para quien aspiraba a tener y conservar el trono.

El monarca no tuvo tiempo, sin embargo, de establecer en Roma las bases de su poder, ya que el conflicto con Decébalo en el Danubio le proporcionó una ocasión para marcharse de la Urbe, dejando de nuevo a sus colaboradores que se hicieran cargo de su posición allí mientras él iniciaba una acción militar que debía llevarle de nuevo a Roma pero con una posición reforzada por la victoria. Hasta el triunfo final, el año 107 (mayo-junio. Kienast, 1996, 122), Trajano no se decidió a instalarse definitivamente en la capital del estado. En el nuevo escenario, asumió plenamente sus tareas como gestor político, cabeza de la administración y padre de la patria (Bennett, 2001, 85-103). A la fortitudo y a la securitas tenía la obligación de incorporar ahora la civilitas, iustitia y clementia. El programa del Panegírico debía completarse (Plácido, 1993, 174-180).

La nueva situación que se crea a partir del 107 no debió ser cómoda para todos. El Príncipe volvía a Roma, y con él llegaba la oficina imperial, que había estado desplazada al Danubio. Los siguientes años los dedicó Trajano a desarrollar la mayor parte de su tarea política, pero también a recabar el apoyo de las élites senatorial y ecuestre, así como de la opinión pública romana. Todos ellos eran súbditos de un monarca a quien apenas habían visto desde el comienzo de su reinado nada más que en los retratos escultóricos y monetales. Se inició entonces el gran programa constructivo del reinado (Packer
1997; Trunk 1993 y 2003), que dotaría a Roma de un elemento identificativo del nuevo monarca: el foro y sus edificios asociados. El protagonista de la decoración de las nuevas edificaciones fue la victoria dácica. De esta manera se creaba una imagen del Príncipe asociado a lo que se consideraba por entonces su obra por excelencia, que sería recordada por futuras generaciones (Aur. Vict., De Caesaribus 13, 5; Amm. Marc. 16, 10, 15). Trajano se presentaba en Roma, ante los ojos de todos sus súbditos, como el gran artífice de la seguridad del imperio, utilizando esta imagen para hacerse con el control de la ciudad e iniciar así su verdadera tarea como gobernante.

El tema identificativo del monarca fue, a partir de entonces, la cuestión dácica. Aunque se había iniciado el proceso para incorporar los nuevos territorios como una provincia del imperio, la postura del régimen consistió en centrarse exclusivamente en los aspectos militares: la guerra, la victoria, el aniquilamiento del peligro dacio. La obtención de la cabeza de Decébalo representó la culminación de la tarea (Speidel, 1970, 172 ss.). En Roma, la gran inscripción del nuevo foro iba a llevar la expresión "ex manubiis" (Aul. Gell 13, 25, 1), la columna recordaría en sus relieves el desarrollo de los acontecimientos bélicos con una profusión de detalles que la convertía en una verdadera crónica de la guerra, y las acuñaciones monetales priorizaban los motivos relativos al conflicto. Entre los años 103 y 111 se acuñó un buen número de emisiones monetales de difícil identificación cronológica en su mayor parte, debido al largo intervalo de tiempo transcurrido entre el V y el VI consulados de Trajano ${ }^{4}$. Entre ellas estaban las que hacían referencia a las conquistas en el bajo Danubio, con las leyendas Victoria dacica y Dacia capta, que lanzaban el mensaje en todos los valores monetales. Los motivos decorativos que acompañaban a estas leyendas hacían referencia exclusivamente a los aspectos militares. El Príncipe como miles aplastaba la resistencia en forma de dacio vencido, o bien la personificación del territorio se manifestaba en actitud vencida sobre los expolia. Junto a ellas, el anciano barbudo que representaba al Danubio recordaba el lugar en el que Roma, una vez más, había impuesto su fuerza militar. Vista con perspectiva histórica, la referencia al río parece sobre todo la expresión del lugar hasta el que las legiones habían llegado y vencido, pero

4. El tema dácico en las monedas del reinado de Trajano ha sido tratado específicamente, entre otros, por: Belloni (1982); Garzón (1988); González-Conde (1991, especialmente 21-25); Chaves (1993, 100-107); Richier (1997). 
para un romano, significaba ante todo el símbolo que delimitaba la romanidad, sacralizado desde la muerte de Augusto, que ahora se había traspasado.

La victoria sobre Decébalo proporcionó a Trajano una herramienta útil para las adhesiones políticas que tanto necesitaba. La vuelta de un príncipe victorioso no era el momento de cuestionar su poder, así que el período que se inauguraba supuso, con toda seguridad, la reafirmación del principado de Trajano y la aceptación del proceso por sus adversarios políticos. El monarca pudo dedicarse entonces a una labor necesaria como el primer cives de Roma, que cuidaba de la población de la urbe y de Italia. Para la vertiente social de esta actividad, copió el programa político de su predecesor, que había iniciado una labor de asistencia alimentaria, dotándose así Trajano de uno de los elementos que más fomentaba una imagen paternalista del régimen. La protección social vino acompañada de una febril actividad constructiva que dotó a la ciudad de Roma de un nuevo referente urbano, el foro de Trajano y sus edificaciones adyacentes, presentados directamente a la población como el resultado de los beneficios económicos de la conquista dácica. La expresión "ex manubiis" y el conjunto decorativo del foro, incluidos los relieves de la columna, proporcionaban la imagen de una victoria lejana $y$, con ello, la de un príncipe demasiado alejado de la ciudad que ahora tenía que integrarse de nuevo en ella mediante la imagen de victor con la que era representado. Todo este programa constructivo se llevó también a los motivos decorativos de los reversos de las monedas que acuñó el estado romano. Las imágenes de la columna ${ }^{5}$ y del foro se representaron en esos años como parte de un programa numismático en el que el tema de Dacia aludía exclusivamente a la conquista: la victoria, el emperador victorioso y el reino derrotado.

Sin embargo, la visión que se representó tenía exclusivamente una vertiente militar. Las

5. La gran columna colocada en el foro con los relieves de las dos guerras dácicas tuvo un especial protagonismo. El monumento fue motivo decorativo de reverso en algunas de las emisiones de todos los valores monetales a partir de su finalización en el año 111 y hasta el final del reinado, destacando especialmente los dupondios y ases del período 114/117, tanto por la cantidad de series como por la variedad de sus detalles decorativos. En oro y plata: RIC II n. ${ }^{\circ} 235$ (año 111); n. ${ }^{\circ}$ 238, 239, 292 y 293 (años 112/114); n. ${ }^{\circ} 307$ y 313 (años 114/117); n. 379 (híbrida). En otros valores: RIC II n. ${ }^{\circ} 579$ y 580 (datada en el período 103/111, pero sin duda del 111); n. ${ }^{\circ} 600$ a 603 (años 112/114); n. ${ }^{\circ}$ 677-683 (años 114/117) nuevas construcciones constituían el aprovechamiento civil de la victoria, mediante la transformación urbanística, pero el monarca aparecía en ellas como el general artífice personal de la victoria. Se evitó deliberadamente la mención a las consecuencias de estas acciones. A partir del año 106, el estado romano tuvo que iniciar la tarea administrativa de crear una nueva provincia, con lo que esto suponía de necesidades de desarrollo urbanístico, de creación de un cuerpo funcionarial y de acantonamiento de un ejército estable para gestionar la paz bajo dominio romano. En cambio, el proceso administrativo no se manifestaba en el aparato propagandístico de los años siguientes a la victoria. Probablemente la anexión de los territorios transdanubianos tendría una importante oposición en Roma. Era mucho más fácil el recurso propagandístico de la victoria y del botín inmediato. Así lo reflejan las acuñaciones monetales como principal herramienta de difusión de los mensajes del poder romano. Los temas elegidos para acompañar a la construcción de la gran obra del foro no aludían a la creación de la provincia, a pesar de que la anexión y la organización provincial se iniciaron pronto (Wachtel, 1990).

El año 106 d.C., Roma comenzó el proceso de incorporación de dos nuevas provincias al territorio del imperio: Dacia y Arabia. Ambas anexiones siguieron caminos muy diferentes. Dacia era el fruto de una conquista y como tal se presentó. Arabia Petraea, en cambio, se formó a partir de las posesiones del reino nabateo sin necesidad de conflicto bélico, lo que en la práctica representaba una gran oportunidad para el Príncipe de presentarlo, ante la oposición política, como el resultado de una eficaz gestión de los asuntos orientales durante el reinado. La anexión de Arabia proporcionaba beneficios al imperio sin ocasionar los gastos de una guerra. El asunto estaba listo también para su uso político y así se hizo en varias series monetales correspondientes al quinto consulado de Trajano y anteriores, en consecuencia, al 111 d.C. (Bennett, 2001, 172-182).

A partir del año 112, el imperio se encuentra inmerso en una gran operación de transformación de la política oriental, con la preparación de una guerra contra los Partos que parecía ya irremediable. La táctica de la guerra requería el traslado de grandes contingentes de legionarios hacia la frontera oriental. Sin embargo, los cambios no se limitaron a las prioridades de estrategia militar, sino que se produjeron en un momento político en el que se inauguraba una nueva etapa del gobierno de Trajano también en lo que 
se refiere a su política interior. El Príncipe había permanecido en Roma desde la victoria sobre los dacios y había contado con unos años para asegurar las bases de su poder. Las dificultades de esos años quedan patentes en las noticias que de forma parcial y sesgada transmiten las fuentes literarias sobre algunas conspiraciones. Trajano había heredado del breve reinado de Nerva una situación inestable en la que éste había tenido ya que hacer frente a la conspiración de Crassus, castigada con el destierro, y sobre todo a los deseos de promoción al trono de M. Cornelius Nigrinus Curiatius Maternus. Dión Cassio transmitió varias noticias relativas al reinado que cobran una especial importancia, no sólo por la información proporcionada, sino por la estructura elegida en esa parte de la obra para ordenar los acontecimientos (68, 15, 5 (3) y ss.; 16,3 y 17). A partir de la afirmación de que Trajano honró a los hombres buenos e ignoró a los que no lo eran (Cassius Dio 68, 6, 4), iniciaba el relato de algunos episodios que, con mayor o menor claridad, aludían a conspiraciones reales o ficticias contra su figura. El autor ponía nombres a esa dualidad de individuos que rodeaban al monarca, ocupándose primero de los más fiables. El propio Sura se vió envuelto en rumores de conspiración (Cassius Dio 68, 15, 3.2 ss.) que el monarca habría obviado, acudiendo a su casa para demostrar a todos que no había fisuras en el núcleo del poder. Tanto si los rumores eran ciertos como si no, se iniciaba con el episodio de Sura un relato encaminado a demostrar que, durante el reinado de Trajano, se había premiado la honestidad y la fidelidad frente a otros valores. El mismo Príncipe habría ofrecido su espada a su prefecto del pretorio para que le defendiera o atacara según sus méritos y su comportamiento, demostrando así que nadie quedaba fuera de esa obligación (Cassius Dio 68, 16, 1.2). El respeto del monarca hacia los más fieles de entre los padres de la patria se demostraba con la erección de estatuas, como ocurrió en el caso de Sosius, Palma y Celsus (Cassius Dio 68, 16, 2). En cambio, las traiciones demostradas se castigan, como ocurrió con Crassus (también SHA, Vita Hadr. 5, 6-7).

Todo esto lo contaba el autor severiano como una reflexión a partir de la muerte de Sura (ca. 110), mezclando acontecimientos del reinado y situándolos en un momento que, en el discurso temporal, correspondía a los años en los que Trajano había permanecido en Roma, durante el período entre guerras. A continuación (Cassius Dio 68, 16, 3), hablaba de la construcción del foro, de la basílica y de la columna, las grandes construcciones que culminaban el pe- ríodo de estancia del monarca en la ciudad. En seguida (Cassius Dio 68, 17), empezaba el relato de la campaña contra los partos, sin separación con respecto a los temas anteriormente tratados. La estructura del relato indica que el autor severiano centró los acontecimientos de esa etapa del reinado en dos asuntos principales: la lucha contra las conspiraciones, es decir, la supresión de sus rivales políticos, pero también de toda sombra de duda sobre la cohesión del grupo de poder; y la construcción de los grandes edificios públicos que simbolizaban la grandeza de la victoria sobre los dacios y sus beneficios económicos. Este esfuerzo constructivo desembocó en una serie de inauguraciones que, no de forma casual, constituyeron el preludio de la salida hacia oriente para la última gran guerra del reinado, y cuyo relato iniciaba Dión Cassio a continuación (Cassius Dio 68, 17, 1 ss.), recogiendo así una tradición en la que se mantenían las principales preocupaciones de los años centrales del reinado. La acción de salvaguarda de la República, presentada por Dión como una de los principales iniciativas de Trajano, escondía en realidad una operación de limpieza política semejante en calidad, aunque no en cantidad, a la llevada a cabo por Domiciano contra los sectores senatoriales hostiles a su persona. La diferencia es que ahora no se realizó una represalia generalizada, sino que se presentó ante la opinión pública romana la imagen de un monarca capaz de revertir en la ciudad y en su población los beneficios económicos de la victoria contra las poblaciones del bajo Danubio. Esta orientación evitaría una crisis política de largo alcance, proporcionando al monarca los apoyos suficientes ante la opinión pública como para que los sectores senatoriales más hostiles no pudieran tocarle. Decébalo había dado a Trajano, indirecta e involuntariamente, la fuerza que necesitaba para recabar apoyos políticos en Roma.

Sin embargo, esa proyección de la imagen del monarca, posible a partir de una victoria, dió paso a un proceso mucho más complejo, en el que se produjeron una serie de cambios ya analizados en la historiografía contemporánea sobre el tema. E. Cizek (1993, 385-401) definió el cambio producido desde el año 112 como una evolución prudente y sin conflicto abierto hacia el absolutismo, adornado con una fascinación por la imagen de Alejandro. El proceso se habría iniciado a partir del año 111, más claramente desde el 112, y contaría con algunos elementos nuevos en el reinado, especialmente la proyección dinástica de los Ulpii y una nueva teología imperial que cambiaba la relación del Príncipe 
con las divinidades. El autor rumano realizó uno de los más completos trabajos de esta etapa. Se podría añadir, sin embargo, que este cambio no puede explicarse sin analizar la acción política anterior. Desde la vuelta de Trajano en el año 107 (mayo-junio, Kienast, 1996, 122) y a lo largo de esos años de su presencia en Roma, se sientan las bases de la posición política de Trajano, que le permitiría después atreverse a utilizar nuevos elementos en su proyección pública. De todos ellos, el más representativo de la nueva posición del monarca fue el nuevo papel de los Ulpii, impensable unos años antes y que les proporcionaba por fin la posición pública de una familia imperial, como quedaba patente con la presencia de Plotina, Matidia y Marciana en las acuñaciones correspondientes al VI consulado de Trajano (1 enero del 112). Especialmente significativa fue la puesta en valor de la figura del padre biológico de Trajano, que dotaba a éste de un precedente dinástico que le igualaba a los Cocceii, reivindicando el prestigio de su propia gens $^{6}$. La posesión de una genealogía imperial había sido una cualidad de la mayoría de los príncipes anteriores a partir de Augusto. Primero los julio-claudios y luego los Flavios presentaron un parentesco que reforzaba la elección del "capax imperii". Trajano construyó desde 111/112 la imagen de una nueva familia imperial ${ }^{7}$ que pudiera perpetuarse en el trono como lo habían hecho sus predecesores, aunque su proyecto no iba a pasar de la generación siguiente. Lo tardío de la iniciativa dinástica del monarca se debió a que, hasta ese momento, su situación política no le habría permitido un atrevimiento semejante.

Hacia el 112 ya era evidente que el monarca había basado su poder en la fuerza derivada de una política exterior agresiva, que no se debía exclusivamente a su deseo de aumentar los recursos del imperio ni a la búsqueda de solucio-

6. Así se plasmó en monedas acuñadas durante el VI consulado de Trajano (año 112), que reunían los nombres y los retratos de Nerva y de Trajano padre. La divinización de M. Ulpius Traianus, el padre biológico del Príncipe, se ha calculado ca. 113, discutiéndose si murió en esa fecha o en los años anteriores. Vid. nota 7. Sobre este debate, vid. Plinio, Paneg. 89, 2; Durry (1965, 51 ss.); PIR 2, V 574; Caballos (1990, 308). Para su importancia política: Alföldy (2000, 11 ss.).

7. Una emisión de denarios fechada en 112/114 evitaba el cognomen Nerva en la onomástica imperial: RIC II Trajano, n. ${ }^{\circ} 238$. En monedas de $112 / 114$ en todos los valores: Divus Traianus Pater (RIC II Trajano n. ${ }^{\circ}$ 251, 252, 726 y 727). También a partir del año 112 se hicieron acuñaciones senatoriales con el nombres de Plotina, Marciana y Matidia (RIC II n. ${ }^{\circ} 728$ ss.). nes en las fronteras, sino también a la necesidad de encontrar fuera de Roma lo que ésta le negaba en forma de apoyos políticos suficientes para asegurar su permanencia y la de su familia en el trono imperial. La nueva etapa se inauguraba con la aceptación del VI consulado por parte de Trajano (ocupado desde 1 de enero de 112) que no había desempeñado esa alta magistratura desde el año 103, recién conseguidos la victoria en la primera guerra dácica y el propio título $D a-$ cicus. Sin duda lo dilatado del tiempo entre ambos consulados era una cuestión de prudencia política para frenar la animadversión de algunos senadores. El Príncipe disfrazaba de moderatio lo que en realidad era debilidad en los apoyos con los que contaba.

Si bien los años de permanencia de Trajano en Roma (107-112) habían servido para ampliar su base política, al final de esta etapa se iban a producir algunos cambios en los círculos más próximos al monarca. La preparación de la guerra oriental llevó consigo algunos nombramientos que dejan una duda sobre las verdaderas simpatías del monarca. El nombramiento de Adriano como gobernador de Siria, que ponía en sus manos el control de la provincia estratégicamente más importante para el ataque a Partia, ha hecho pensar (Bennett, 2001, 184) que quizá Trajano sí tenía previsto que fuera su sucesor aunque no se hubiera atrevido a hacerlo evidente hasta ese momento. Por otra parte, en el escenario de posibles cambios personales en el círculo más próximo al Príncipe, no se puede olvidar el giro que dió la carrera pública de un personaje tan influyente como $L$. Minicius $\mathrm{Na}$ talis (PIR ${ }^{2} \mathrm{~V}, \mathrm{n} \cdot{ }^{\circ}$ 619), hasta entonces uno de los hombres más cercanos al Príncipe, a quien acompañó en la primera guerra dácica. El año 106 alcanzaba el consulado (consul suffectus), iniciando un período de permanencia en Roma que coincidía con la presencia del Príncipe allí y durante el cual no se paró su promoción personal (fue nombrado curator alvei Tiberis et riparum et cloacarum urbis, ca. 109/110). A partir del año 113, comenzó un largo gobierno provincial en Panonia, que ya no abandonó hasta después de la muerte de Trajano (Caballos 1995, 211 ss.). Este cargo le aseguraba el control sobre una provincia de gran importancia en el entramado territorial romano, pero le alejaba definitivamente y para el resto del reinado del lado del monarca y del centro de gravedad de las decisiones políticas, que a partir de entonces se tomarían desde oriente. La trayectoria de Natalis durante los cuatro últimos años del reinado de Trajano contrastaba con su suerte a partir del ascenso de Adriano al trono, 
durante cuyo reinado alcanzaría el proconsulado de África (Caballos 1990, 226-227, n. ${ }^{\circ} 127$ ) y sería testigo de la promoción personal de su hijo. Sin duda su caso es un ejemplo del alejamiento de Trajano a partir del año 112 con respecto a algunas familias senatoriales en las que se había apoyado y de los cambios en su círculo más cercano. En oriente estaba acompañado de Lusius Quietus, Attianus, el propio Adriano y su familia más directa (Cassius Dio 68, 17, 1 ss.).

Entre los indicios del cambio que se ha producido en el reinado, hay que considerar uno más, que no suele vincularse al proceso y que consiste en el tratamiento de la victoria dácica. Es sabido que, a partir del año 102 y especialmente desde el 106 d.C., las acuñaciones monetales difundieron por todo el imperio la imagen del territorio abatido y de sus habitantes vencidos y humillados (González-Conde, 1991, 21-25). La iconografía utilizó exclusivamente la vertiente militar de la victoria y Roma se vió inundada literalmente con el botín de guerra. Se prescindió de la vertiente civil y del problema administrativo que la conquista generó, a saber, la construcción de una nueva provincia, que necesariamente se inició a partir del final de la segunda guerra. Trajano y su entorno se centraron, como hemos visto, en proyectar la imagen del príncipe victorioso y buen administrador, lo que requería entre otras cosas dejar cerrado el tema de Dacia. Cuando, unos años después, su posición dentro de los círculos senatoriales de Roma había cambiado, se pudo entonces añadir a los elementos difusores de este cambio un nuevo tratamiento del asunto del bajo Danubio. Entre los años 112-114, el Senado romano ordenó acuñar una emisión monetal que recordaba la anexión de los territorios del reino dacio de Decébalo al imperio (RIC II Trajano n. ${ }^{\circ}$ 621-623). La elección del motivo de reverso no era una novedad, sino la sucesión de una serie de temas iconográficos desarrollados en la numismática y en el arte oficial desde el final de la primera guerra dácica en el año 102. Las leyendas relativas al tema rezaban Dacia capta y Dacia victa, e iban acompañadas de una variada iconografía que incluía diferentes formas de representación del territorio vencido. A estas acuñaciones se venían a unir las de la nueva provincia de Arabia, que bajo la consigna de Arabia adquisita, hacía referencia a la expansión pacífica del imperio. El tratamiento monetal de ambas provincias era, por lo tanto, diferente desde el origen, como variadas había sido su formas de anexión. Pero además, las monedas acuñadas en los años 112-114 condujeron por diferentes caminos a cada una de las provincias. El tema de Arabia se mantuvo sin variaciones en lo que a leyenda se refiere y con muy poca variedad iconográfica. En cambio las monedas de Dacia incorporaban una nueva leyenda (Dacia Augusta provincia $)^{8}$ junto a la personificación del territorio en forma de figura femenina, que conviviría con las anteriores de temas de victoria. De esta forma, habría que distinguir tres etapas en las acuñaciones trajaneas de tema dácico; las dos primeras con tratamiento militar, desde 102 y desde 106 respectivamente; y la tercera con un mensaje civil de carácter administrativo, a partir del 112. Los sestercios y dupondios que llevaban desde esa fecha la nueva leyenda eran acuñaciones de responsabilidad senatorial, aunque, a esas alturas, es difícil admitir que los mensajes monetales difirieran de las consignas políticas del régimen. El nuevo lema era un recurso que se había evitado deliberadamente hasta entonces por pura conveniencia política. El objetivo de este cambio de orientación era doble: por una parte se podía presentar ya la construcción provincial como un hecho acabado y resuelto; y por otra, servía a los intereses de política exterior que se estaban preparando para oriente. Es posible que el Príncipe, necesitado de reafirmar su poder, no quisiera o no pudiera presentarse antes del 112 como aquel gobernante que establecía por primera vez un limes transdanubiano. A partir de esa fecha, el trabajo del Príncipe como difusor de la romanidad era una idea muy útil para su nuevo proyecto oriental, que iba a significar el ataque a un gran estado de más allá del Éufrates, con el consiguiente desgaste económico y humano que Roma debería asumir. De forma paralela, las monedas que conmemoraban el funcionamiento de los Alimenta (sestercios, ases y dupondios con la leyenda Alimenta Italia), presentaban una alegoría de Abundantia que complementaba la orientación de años anteriores. Trajano aparecía como el salvador del estado y de sus habitantes, cuidaba las fronteras y distribuía entre la población itálica los resultados económicos de su política fronteriza. La expansión del limes había proporcionado la prosperidad a Italia. Como recordaba E. Lo Cascio $(2000,312)$ no era casual que este fuera el mensaje del primer príncipe de origen provincial.

8. RIC II Trajano n. ${ }^{\circ} 621-623^{a}$. Se trata de sestercios y dupondios fechados en 112/114, que llevan en el reverso la leyenda DACIA AUGUST[A] PROVINCIA, además de una representación de la personificación femenina de la provincia sentada en una roca y rodeada de niños que llevan productos de la tierra. 
En definitiva, a partir del año 107, Trajano inició la que sería su estancia más larga en Roma durante sus años de gobierno. La victoria dácica le proporcionó la posición suficiente para aumentar sus apoyos políticos en los círculos senatoriales, que verían ahora como inevitable el sometimiento al monarca. Los recursos de la guerra los empleó en proporcionar a la población de Roma una muestra de los beneficios económicos de la victoria sobre Decébalo, en forma de grandes construcciones públicas y de desarrollo de la institución alimentaria. A partir del año 112, con un poder asentado sobre bases firmes, pudo tomar una serie de iniciativas que tenían un doble objetivo: en primer lugar, la realización de un proyecto oriental que debía servir para asegurar la frontera y para sustentar a un sector senatorial expansionista que apoyaba al Príncipe y que utilizaba la guerra para el beneficio político y económico de ellos y sus familias; en segundo lugar, la proyección de una imagen dinástica inexistente hasta entonces y dirigida a mantener el poder de Trajano y de la gens Ulpia. La transformación de los mensajes políticos a partir del año 112 era la demostración del camino que el gobernante se había ido trazando. La elaboración histórica de las siguientes generaciones de romanos alegó razones ideológicas para este proceso, tales como la megalomanía trajanea o la evocación de Alejandro. Una vez más se disfrazó de ideología lo que no eran más que decisiones marcadas por la coyuntura histórica y la conveniencia política de un sector de la élite romana, acostumbrada a parasitar los recursos del estado y que luchaba por su parcela de poder dentro del sistema.

Profa. Pilar González-Conde

Area de Historia Antigua

Dpto. de Prehistoria, Arqueología

$\mathrm{H}^{\mathrm{a}}$ Antigua, Filología Griega y

Filología Latina

Universidad de Alicante

030080 Alicante

pilar.gonzalez@ua.es

\section{BIBLIOGRAFÍA}

ALFÖLDY, G. y HALFMANN, H., 1973: El edetano M. Cornelius Nigrinus Curiatius Maternus. General de Domitiano y rival de Trajano. Trabajos Varios del S. I. P. n. ${ }^{\circ} 44$, Valencia, 1973 (= Chiron 3, 1973, pp. 331-373).

BENNETT, J., 2001: Trajan. Optimus Princeps, London-New York, $2^{\text {a }}$ ed.

CABALLOS RUFINO, A., 1990: Los senadores hispanorromanos y la romanización de Hispania, Tomo I: Prosopografía, Sevilla.

CABALLOS RUFINO, A., 1995: "Los magistrados del orden senatorio originarios de Hispania en las provincias norteafricanas durante el alto imperio romano", Actas del II Congreso Internacional El Estrecho de Gibraltar. Congreso Internacional del Estrecho de Gibraltar, vol. 2, 211-236, Ceuta.

CIZEK, E., 1983: L'Époque de Trajan. Circonstances politiques et problèmes idéologiques, Bucaresti-Paris.

FEDELI, P., 1989: «Il Panegirico di Plinio nella critica moderna», Aufstieg und Niedergang der römischen Welt II, 33.1, 387-514, Berlin.

GONZÁLEZ-CONDE, M. ${ }^{a}$ P., 1991: La guerra y la paz bajo Trajano y Adriano, Madrid.

KIENAST, D., 1996: Römische Kaisertabelle. Grundzüge einer römischen Kaiserchronologie, Darmstadt, $2^{\mathrm{a}}$ ed.

MATTINGLY, H. y SYDENHAM, E.A., 1926: Roman Imperial Coinage, II: Vespasian to Hadrian, London.

PACKER, J., 1997: Trajan's Forum: A Study of the Monuments, Berkeley.

$\mathrm{PIR}^{2} \mathrm{~V}$ = PETERSEN, L., 1983: Prosopographia Imperii Romani saec. I, II, III. Editio altera. Pars V.2, Berlin.

$\mathrm{PIR}^{2}$ VI = PETERSEN, L. y WACHTEL, K., 1998: Prosopographia Imperii Romani saec. I, II, III. Editio altera, Pars VI, Berlin.

PLÁCIDO, D., 1993: "El Optimus Princeps, una imagen del emperador entre tradición y renovación”, en GONZÁLEZ, J. (ed.), Imp. Caes. Nerva Traianus Aug., 173-186, Sevilla.

RICHIER, O., 1997: "Les thèmes militaires dans le monnayage de Trajan", Latomus, 56.3, 594-613.

SPEIDEL, M., 1970: "The captor of Decebalus. A new inscription from Philippi", Journal of Roman Studies 60, 142153.

STROBEL, K., 1984: Untersuchungen zu den Dakerkriegen Trajans, Bonn.

TRILLMICH, W., 2000: "El Optimus Princeps, retratado por Plinio, y el retrato de Trajano", en GONZÁLEZ, J. (ed.), Trajano emperador de Roma, 491-507, Roma.

TRUNK, M., 1993: "Das Traiansforum. Ein steinernes Heerlager in der Stadt?", Archäologischer Anzeiger, 1993.2, 285-291.

TRUNK, M., 2003: "La actividad constructora de Trajano en Roma", en ALVAR, J. y BLÁZQUEZ, J. Ma (eds.), Trajano, 257-268, Madrid.

WACHTEL, K., 1990: "War D. Terentius Scaurianus der erste Statthalter Dakiens?", Klio, 72.2, 473-477.

WATERS, K. 1969: "Traianus Domitiani Continuator", American Journal of Philology, 90, 385-405. 